\title{
[REVIEW]
}

\section{Pluralism in Species Concepts: Dividing Nature at its Diverse Joints}

\author{
Ronald Sluys' and Cornelis J. Hazevoet ${ }^{2}$ \\ 'Institute for Systematics and Population Biology. Zoological Museum, University of \\ Amsterdam, P. O. Box 94766, 1090 GT Amsterdam, The Netherlands \\ ${ }^{2}$ Museu e Laboratorio Zoologico e Antropologico (Museu Bocage), Ruae Escola Politecnica 58. \\ 1250 Lisboa, Portugal
}

(Received 20 August 1998; Accepted 12 February 1999))

\begin{abstract}
The paper outlines the current discussion on the species problem: what actually is a species and how do we recognize such an entity in nature? Six of the major species notions are briefly explained. A distinction can be made between species concepts based on the process of interbreeding and concepts that focus on common descent. Application of these different types of species concept may give incompatible results. It is discussed to what extent we can be certain that the species delimited represent objective realities in nature and are independent of the discovery procedure applied. Further, it is argued that because of the existence of various evolutionary processes, nature can be divided into several natural entities, each representing a species of some sort. The choice of a particular species concept is determined by that aspect or process in nature that forms the focus of one's research agenda. This plea for pluralism should preferably not affect taxonomic procedure; named species taxa should be based on only one, taxic species concept.
\end{abstract}

Key Words: species concept, interbreeding, reproductive isolation, phylogeny, ontology, pluralism, taxonomy

\section{Introduction}

The species category is important for every biological discipline and continues to function in such diverse fields as the estimation of global biodiversity (Groombridge 1992), conservation biology (Rojas 1992; Geist 1992; Easter-Pilcher 1996; Hazevoet 1996; Cracraft 1997), and population biology (Avise 1996). However, there is also ample recent literature discussing the species problem, i.e. the situation that biologists are not really sure what sort of things species are and how to discover such entities in nature. Because in all kinds of studies species are generally seen as a basic unit, in one way or the other, this uncertainty has resulted in a proliferation of species concepts and definitions (cf. Sluys 1991; Zink 1997; Mayden 1997). Recently, the discussion historically has come full circle in that Mallet (1995) suggested a return to nominalism, i. e. to use the pre-Darwinian and Darwin's own notion that the species idea merely represents an operational tool for organizing and classifying an otherwise bewildering biodiversity. We fail to see that resurrection of nominalism in the species debate contributes to modern science and that an operational, man-made grouping can tell us something about the real process of evolution, as claimed by Mallet (1995) (see also Mayr 1996: 263).

Mallet's quandary may be the result of the fact that he, like others (Kornet 1993; Mahner 1993), is focusing too much on finding a single, common definition of species. 
We believe that this narrow focus on a common definition is misguided for two reasons. First, it was already pointed out by Popper (1977: 14) that "definitions do not play any very important part in science". A definition is a specification of a concept (Blackman 1995; Sluys 1996) and one concept can be the basis for several practical definitions. A concept provides a mental window through which we observe the world, while definitions relate to the operational tools for discovering species (see also Blackman 1995; Baum and Shaw 1995; Baum and Donoghue 1995). Therefore, species concepts should be our major concern (contra Mallet 1995). Second, we are of the opinion that adherence to a single species concept or definition (some workers make no clear distinction between these two) as the all-embracing characterization of the species category has already been shown to be the wrong approach to the species problem and to hamper further understanding (Sluys 1991).

Nevertheless, it is all too frequent that recent papers neglect this necessary broad, pluralistic perspective of the nature of species. In this paper we promote a pluralistic approach of the species notion and argue that pluralism in species concepts reflects different research interests.

\section{Where to choose from? Species concepts in brief}

The available species concepts stress different aspects of nature's diversity and its evolution. Zink (1997) listed 29 different concepts and views of species, a figure that is approached by Mayden's (1997) list of 22 species concepts. Here we present a sample of the more widely used or more precisely formulated concepts. These can be grouped or dichotomized according to different common denominators such as: temporal/nontemporal, process/pattern, systematics/evolution, structural/historical, interbreeding/ecological/phylogenetic. The most apparent dichotomy, however, is between species concepts that emphasize process as a grouping criterion and those that concentrate on pattern of diversification. Within each main grouping several subdivisions can be made. We find the classification presented in Fig. 1 useful for our purpose, but others are possible. The more important characteristics of each of these concepts are as follows.

The ecological concept sees species as lineages (or closely related sets of lineages)

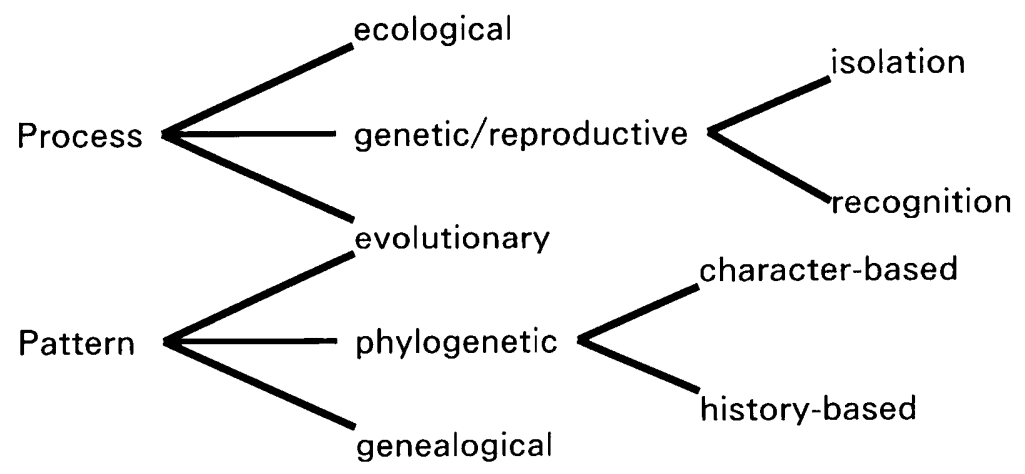

Fig. 1. A classification of some current species concepts. 
that occupy an adaptive zone minimally different from any other such lineages in its range and that evolves separately from all lineages outside its range (Van Valen 1976), thus laying great emphasis on the putative process of adaptation. A lineage is defined as a clone or an ancestral-descendent sequence of populations, and an adaptive zone as some part of the resource space together with whatever predation and parasitism occurs on the group considered. Note that the ecological concept perhaps belongs to the ecological hierarchy of nature rather than to the genealogical hierarchy (see below).

For the genetic concepts, the most important property of species is their acting as gene pools or, more precisely, as the field for gene recombination. This emphasis on the role of genes is based on the idea that an insight into various microevolutionary phenomena automatically leads to an understanding of the mechanisms of biological diversification. Genetic concepts have been mainly formulated and favoured by population biologists working with biological diversification over short time intervals.

Since its conception (Mayr 1942), the isolation concept has been for many years the most popular view of species among vertebrate biologists. It maintains that species are characterized primarily by their reproductive isolation from other groups of organisms, i. e. the actual or potential ability for gene exchange is perceived as the crucial grouping criterion. However, its requirement for judgments about the potential ability for interbreeding among taxa may give rise to unwarranted and potentially misleading speculations, leading to the recognition of paraphyletic or polyphyletic taxa. In practice, the isolation concept is not very different from the local naturalist's view of species and it is difficult to apply across time and space.

In an attempt to circumvent some of the isolation concept's difficulties in application, Paterson (1985) formulated the recognition concept. As in the isolation concept, common fertilization systems are of prime importance to the recognition concept, but here these are defined through specific mate recognition systems, thus de-emphasizing the need for complete genetic isolation as a grouping criterion. A species is not defined relationally, but by the functioning of fertilization mechanisms, the rationale being that, of necessity, all sexual organisms must possess an effective fertilization system and species are, therefore, the incidental consequences of adaptive evolution.

The evolutionary concept combines elements of both process- and patternoriented concepts because on the one hand it envisages species as entities that maintain their identity through time and over space (i.e. a requirement of pattern), but it also equates species with the largest tokogenetic unit, which may imply both actual or potential ability for gene exchange. According to Wiley (1981), the evolutionary species concept is a lineage concept that avoids many of the problems of the isolation concept without denying that interbreeding among sexually reproducing individuals is an important component of species cohesion, thus providing a bridge between evolutionary process and pattern of descent.

Phylogenetic concepts were formulated when it was realized that genetic concepts were inappropriate tools for phylogenetic systematics, particularly because the potential for gene exchange is only loosely connected to historical relatedness. Of the phylogenetic concepts, those that are character-based seek to discover the smallest (irreducible) diagnosable cluster of organisms that show a parental pattern of ancestry and descent (Cracraft 1983, 1987). Diagnosability may be based on any (set 
of) character(s) that can be inferred to have a genetic basis. However, the relatively simple criterion of diagnosability may lead to inconsistencies that oppose the concept's goal, i.e. to provide a species concept appropriate for phylogenetic systematics, since it may result in species defined solely by plesiomorphies.

History-based phylogenetic concepts argue that the notion of monophyly should be included as a grouping criterion (Mishler and Brandon 1987). However, monophyly in its usual meaning of intertaxic relationships is difficult - or perhaps impossible - to apply at the species level, while when a more loosely perceived idea of monophyly is permitted, it is found that monophyletic groups occur at all levels of the genealogical hierarchy, including species, populations, and demes. One outcome of discussions on these issues has been the genealogical concept, which pictures species as basal and exclusive taxa containing no subgroups that are themselves exclusive; i.e., basal groups of organisms are those whose genes coalesce more recently with each other than with any outside organisms. A group is exclusive when all of its component organisms are more closely related to each other than to any organism outside the group. The novelty of the genealogical concept is that it defines relationship on the basis of the entire genome and with the help of coalescent theory. A group of organisms forms an exclusive group, or a species, when every gene in every organism within the group derives from a most recent common ancestor within the group and no gene can be derived from an ancestral gene outside of that group (Baum and Donoghue 1995). It must be noted that application of the genealogical species concept is difficult and that for practical purposes it has been advised to use operational criteria such as diagnostic phenotypic variation and reproductive isolation (Baum and Donoghue 1995).

For more extensive discussion of the above-mentioned species concepts, and others as well, we refer to Hull (1997) and Mayden (1997).

\section{Processes}

Under an evolutionary view, one wishes to discover species entities that exist in the real world (contra Stanford 1995), which implies that species must be the result of evolutionary processes and/or participate in such processes. Species are groups of organisms and the number of evolutionary processes in which organisms may participate or be subjected to is very large. Two processes that have received much attention in this context are that of common descent (in the sense of monophyly) and interbreeding (or its related aspect: reproductive isolation). Each of these two processes provides a basis for the systematization or recognition of natural groups of organisms (Graybeal 1995). However, it has been amply discussed and demonstrated that practical application of the species concepts based on interbreeding or descent results in groups of organisms that are not necessarily identical. Application of the criteria of common descent and interbreeding/reproductive isolation to a group of organisms may produce incompatible results in the groupings of these organisms into species (Sluys 1991; Zink and McKitrick 1995; Zink 1996).

However, there are more evolutionary processes than interbreeding and descent operating in nature. Examples of other processes are selection, genetic homeostasis, and developmental canalization. On the basis of participation in one of these other processes, again other species can be recognized as coherent entities. Together, the 
various processes divide biodiversity into at least three major classes of species, viz. interbreeding, ecological, and phylogenetic units (Ereshefsky 1992). Within each class, several species notions can be distinguished, depending on particular aspects of the processes (e.g. isolation and recognition concepts within the class of interbreeding units).

Whether species really participate in biological and evolutionary processes or are merely resultants of such processes has been a matter of debate in the past (see Sluys 1991) and is an issue that is also important in the present context. The question whether species are interactors and/or resultants is closely linked to the notion that, philosophically speaking, species are individuals, for it is only an individual that can undergo biological processes or be their historical effect (for a recent expose of the individuality thesis, see Ghiselin 1997). Evolutionary biologists have now generally accepted the idea that species are individuals and not classes. Species are spatiotemporally restricted objects with fuzzy borders and a capacity to evolve, all being aspects that cannot apply to class constructs.

Recently, however, this discussion has been reopened and it has been denied that species, and monophyletic groups, represent philosophical individuals or things, i. e. objects with a real existence in nature (Mahner 1993; see also Ax 1995; Mahner and Bunge 1997). According to Mahner (1993), species are not individuals but natural kinds. In order to be considered as an individual or thing, the components of a species must have bonding relations. In Mahner's view there are only true bonding relations (notably reproductive relations) between the individual organisms of a biopopulation, and therefore he concludes that only biopopulations can be considered as individuals. Mahner specifically denies descent as a bonding relation, so that, according to his philosophy, allopatric and allochronic populations cannot together constitute a species-individual because they lack a bonding relation. Such species, i.e. the species category as used by practising biologists, are examples of natural kinds. According to Mahner, natural kinds also have reality in the sense that they are based on objective commonalities of the constituent organisms. The objects of these natural kinds, i.e. the organisms, share certain properties that are not chaotically scattered among them, but are correlated. When species in biology are conceptualized in this manner, they become equivalent to natural kinds or species in other scientific disciplines.

Mahner's (1993: 116) quest for "a universal species concept applicable to all things in the Universe, be they alive or not" has not resulted in a concept that is particularly useful or well founded within the biological domain. This is evident when one realizes that it is precisely the evolutionary relationship of descent, denied by Mahner as a possible bonding relation, that causes the properties among organisms to be correlated. From an evolutionary perspective, what else could be behind the correlation of properties? Although Mahner rejects a well established theory descent with modification - as a causal basis for the perceived correlated properties of organisms, he fails to come up with another covering theory explaining these correlations. Neither are we impressed by his stance that the term species should have the same meaning across all scientific disciplines. As biologists, we do not care what other branches of science consider their species to be. In a similar way it does not seem to bother psychologists and physical chemists that they use the term sublimation for completely different phenomena.

We conclude that the individuality thesis on species is the better supported 
notion, which continues to improve biologists' understanding of the nature and ontology of taxa (for further discussion on natural kinds, we refer to Griffiths (1994) and Mayr (1996) and references therein).

Thus, a species is an individual with organisms as its parts. As such, a species is an entity that behaves as a whole with respect to a particular process (Holsinger 1981). There are two ways in which processes may effect coherence of a species. One way is that through participation in a particular process a group of organisms acquires an emergent property that establishes the group as a discrete unit. Whether or not species have emergent properties is a contentious topic. Possible candidates for such processes acting on the level of species instead of their constituent organisms are species selection/sorting, and "occupying" an ecological niche. However, it has been claimed that the focal level of these two processes is not the species but resides at lower hierarchical levels (cf. Sluys 1991; Mahner 1993; Sterelny 1995). The second manner through which species may acquire their coherence is indeed through processes acting on lower levels, viz. on the constituent organisms. Species are then seen as composed of organisms having biological or evolutionary relations, the latter differing between the contexts of investigation and the processes involved (Kitcher 1984). It is important that in assessing the biological domain in which speciesindividuals function or belong as coherent units, the genealogical and ecological hierarchies of nature are taken into account (Sluys 1991).

\section{Hierarchy}

In another way a hierarchical way of seeing has contributed to our understanding of the nature of species. Recent studies have argued that phylogenetic species reside at the boundary between reticulate and divergent genealogy (Davis and Nixon 1992; Frost and Kluge 1994; Baum and Shaw 1995; Davis 1996). Below this boundary the tokogenetic relationships between individuals result in reticulate genealogical relationships between organisms, whereas above the boundary genealogy is hierarchical, resulting in phylogenetic relations between groups (Fig. 2).

According to O'Hara (1993), the difference between tokogeny and phylogeny would be only a matter of generalization because of the necessary prospective narration of every species concept. However, not every species concept does depend on expectations of the future, e.g. the genealogical species concept (Baum and Donoghue 1995). Furthermore, there is more to the difference between tokogeny and phylogeny than merely a difference of representation or generalization, as claimed by O'Hara (1993). Tokogeny and phylogeny concern different scalar hierarchical levels. In a scalar hierarchy, as opposed to a specification hierarchy, the boundaries between levels are nontransitive and each level is characterized by emergent properties that cannot be reductionistically explained by lower-level characteristics (Salthe 1985). All this implies that there are differences in emergent properties across scalar boundaries and that there is no simple way to generalize across such hierarchical boundaries (Frost and Kluge 1994; Valentine and May 1996). It has been argued that the genealogical species concept suffers from a similar kind of overreductionism in that it casts phylogenetic relationship in terms of tokogenetic relationship, thus confounding distinct scalar hierarchical levels (Frost and Kluge 1994). 


\section{Ontology, Taxa, and Evolutionary Units}

Biologists tackling all kinds of research topics with various scientific approaches, but with species as their models or study objects, need to have some degree of certainty that their species act as units with respect to the processes under study. In other words, one wishes to group organisms into species that represent real entities in nature (sce also Mayden 1997) and that exist independently of the discovery procedures applied (see Stanford 1995 for an opposite viewpoint). Cracraft (1997) recently pointed out that the issue of ontology is underrepresented in discussions on species concepts.

It has been well established that monophyletic groups, or taxa, represent real,

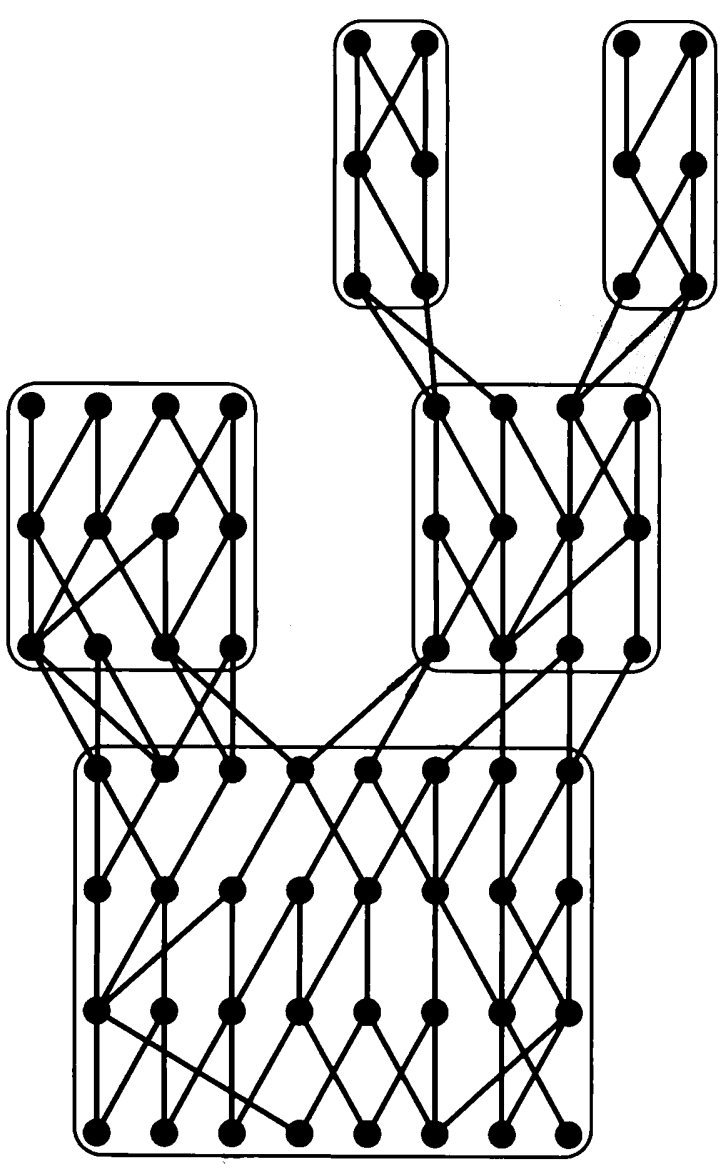

Fig. 2. Diagram of relationships within and among species. Phylogenetic relationships in grey, tokogenetic relationships in black. historical individuals. Thus, if some kinds of species, notably phylogenetic species, are demonstrably monophyletic, then an ontological status is established for at least these species. However, the concept of monophyly does not fare well when applied to species. One obvious problem is that monophyly is defined in terms of species (a single ancestral species and all its descendant species) and therefore cannot apply to the species category itself or to lower-level entities. And when the concept of monophyly is broadened to include a single organism or breeding pair as ancestor (Baum 1992), one ends up with monophyletic groups at all levels of the genealogical hierarchy. As a consequence, one has to apply a ranking criterion in order to determine which monophyletic group constitutes the species. Ranking criteria that have been suggested are ability to interbreed, morphological discontinuities related to the number of synapomorphies between internodes (cf. Sluys 1991 for a review), and exclusivity (Baum 1992; Baum and Shaw 1995; see above). 
Each of these three ranking criteria has its problems concerning practical and theoretical application. Interbreeding is absent between organisms from allopatric populations, while application of this criterion may result in the delimitation of non-historical groups, a result that is incompatible with the concept of monophyly. Ranking least inclusive monophyletic groups or species through morphological discontinuities suffers from a considerable amount of subjectivity in species delimitation. The concept of exclusivity confuses gene phylogenies with taxon phylogeny, while its operational tests resort to diagnostic phenotypic variation and reproductive isolation (Baum and Shaw 1995), which are criteria that have a poor relation with the concept of monophyly.

Considering the fact that (1) apomorphies for species taxa are rare (Sluys 1991; Lee 1995), (2) the concept of monophyly cannot be applied well to the species category, and (3) there is "no biological principle dictating that every re-organization of stored information must lead to a discernable apomorphic modification" (Sluys 1991: 1168), one might abandon the notion of monophyly and its criterion of apomorphy in the determination of species status and resort to diagnosibility of a species. But grouping organisms into species by the diagnostic criterion may result in non-historical groups (Baum and Donoghue 1995). Therefore, Sluys (1991) already argued that the diagnostic approach should have as underlying assumption that the species discovered are monophyletic, but this does not alter the fact that sometimes diagnostic species may comprise organisms that are "para-" or "polyphyletic", in the same way that presumedly monophyletic higher taxa may turn out to be para- or polyphyletic in future studies.

If one does not invoke the assumption that diagnostic species have the same ontological status as species delimited by synapomorphies, i.e. that they are monophyletic by definition, on what grounds can these species then be considered as real? In general, if one abandons the requirement that species must be monophyletic, how can one be sure that the species delimited represent objective realities in nature? Sluys (1991) suggested that the ontological status of diagnostic species may be based on the notion that their cohesiveness derives from shared historical information. According to Zink and McKitrick (1995), diagnosable, plesiomorphic basal taxa are cohesive units, and therefore these authors favour the null hypothesis that these taxa represent species.

Because of this difficulty in applying the concept of monophyly at the species level, biological practice is such that generally species are treated somewhat differently than other, higher taxa. For example, higher taxa would not be used in historical biogeographic studies unless there was some certainty about the monophyletic status of the taxa through the presence of derived characters. However, species taxa are used in all kinds of studies, including historical biogeographic ones, without their ontological status being indicated by apomorphies. This implicitly or explicitly presumed difference between species and higher taxa has been used to argue that species are evolutionary units, in contrast to higher taxa. According to that point of view, evolutionary units are equated with reproductive units (Ereshefsky 1991). However, we have seen already that the reproductive criterion is of no importance for some of the current species notions. Furthermore, some workers have required that evolutionary units are monophyletic (cf. Ereshefsky 1991). Since it has been established that there is no necessary overlap between the criteria of reproductivity and monophyly, the question is: which kind of 
species is an evolutionary unit?

\section{Speciation}

It seems to us that the discussion on the species being an evolutionary unit or not suffers from slackness in specifying the process in which the species is supposed to function as a unit. If one only means that species function as units in the process of speciation, i.e. in the multiplication of units of like kind, then this begs the question: multiplication of what kind of species, involved in or resulting from what kind of processes?

Bush (1994: 286) claimed that "...the process and outcome of speciation ... does not depend on the a priori invocation of any particular species definition" (see also Zink 1996: 3). However, we maintain that species concepts are linked to the specific processes and their specific end results that form the focus of a scientist's research program. Therefore, there cannot be one process of speciation or one kind of end result of these processes. There is a clear link between presumed processes of speciation and species concepts and they are not all alike. Therefore, there is no basis for the claim frequently made by population biologists that "...when we understand the origin of reproductive isolating factors, we understand the origin of species" (Coyne 1992: 511). Such claims are based on a narrow focus on the isolation species concept and suffer from overreductionism in assuming that insights in population genetic processes can be directly extended across scalar hierarchical boundaries or even from ecological to genealogical entities (see also Valentine and May, 1996). To give just one example: knowledge of population genetic processes provides no insight into the origin of phylogenetic species because the latter concern diagnosable entities (under the influence of genetic homeostasis, developmental canalization, etc.) and phylogenetic relationships (that may stand in poor relation to genetic compatibility). Thus, for one particular species notion, the isolation concept, establishment of reproductive isolation is the crucial event, while for other species concepts the initiation of a new lineage or the development of diagnosibility is the yardstick for speciation (Frost and Kluge 1994).

We conclude that there is another reason for not following up Mallet's (1995) suggestion to return to Darwin's nominalistic species notion. We have progressed beyond the title of "On the Origin of Species", since it has become apparent that there is no single origin of one kind of species (Rosenberg 1985).

\section{Pluralism}

It is surprising that for so long biologists have been obsessed with finding the origin of species and the species notion, whereas in the other sciences it has been accepted a long time ago that there are more ways than one to describe natural processes and their outcome. There is no physicist who will consider the description of light either as a particle phenomenon or in terms of wave lengths to be a poorer form of physics. However, many biologists seem to think that a pluralistic approach in biology in general, and towards the species issue in particular, makes a poorer form of biology and forms a retreat from pure, objective, universally valid 
knowledge. However, the history of the sciences illustrates abundantly that very little of science is universally valid, since theories and laws are usually constrained by boundary conditions defining their domain. It is no other with the study of species and speciation. About 140 years after the publication of "On the Origin of Species" it has finally become clear that there is no single way in which we may group organisms into species, i.e. describe biodiversity. The kind of descriptor used will be determined by the aspects of nature that form the focus of our research agendas. There is no single concept that divides nature at its joints (as claimed for the phylogenetic species concept, for example, by Cracraft 1987) because there are several types of joints at which nature may be carved.

The idea that one must be pluralistic in how one regards and uses species concepts is not new. For example, Mishler and Donoghue (1982) and Mishler and Brandon (1987) have argued for a pluralistic approach. However, their pluralism relates to a variety of ranking criteria that can be applied in deciding which of the least inclusive groups are to be ranked as species (Horvath 1997; Hull 1997). Hull (1997) pointed out that the evolutionary and the cohesion concepts are also pluralistic in a weak sense, in that they accept that more than one mechanism can result in the fulfillment of the definitions. Ruse (1998) recently argued also for pluralism in dealing with the species problem. However, his pluralistic approach concerns a consilience of inductions (i.e. the coincidence of different criteria) to arrive at a characterization of a species.

In this paper, however, we argue for a different and much stronger form of pluralism, since we maintain that there is no single preferred way in which living organisms can be grouped into species and that the choice of concepts is governed by one's research interest. And, naturally, one research interest is as valid as another (see also Kitcher 1984, 1987, 1989). This is a form of pluralism that to our mind is inescapable and that has as one of its advantages that it automatically focuses our attention on the interesting, but poorly understood, relationships between the various species-level entities that exist in nature. Contrary to Mayden (1997), and probably many others as well (cf. Hull 1997), we are of the opinion that the history and the current debate on the conceptualization of species have amply demonstrated that at present a pluralistic notion is both natural and logical (Mayden relegates all other existing, secondary species concepts to operational tools of his preferred primary, evolutionary species concept, and accepts pluralism in secondary concepts).

Sober (1984) and recently also Ghiselin (1997) argued against pluralism. However, Sober's arguments mainly concern the idea that species are both natural kinds and individuals. We agree with Sober and Ghiselin that species should be conceptualized as individuals (see above).

In arguing for a pluralistic approach to species concepts we do not wish to propound the idea that the term species has no precise meaning or should be used in an equivocal way in scientific discourse. To the contrary, we argue for a very different kind of pluralism, in which the sense and context of the term species have been specified. It may be that in due time the different species-level units will be referred to by different terms. A necessary first step in that direction is to realize that there are various kinds of natural entities subsumed under the current usage of the term species and that therefore a pluralistic approach may help us in exploring the relations between these various kinds of species-level entities. 


\section{The species as a category in the Linnean hierarchy}

As will be clear to anybody who has looked into the practice of naming species taxa, pluralism is, in a sense, firmly established in taxonomy because widely different criteria have been and are still being employed to delimit and subsequently name species-level entities. For instance, named species of beetles are not necessarily directly comparable to named species of birds, while most species-level taxa in plants have been delimited according to criteria different from those applied to fungi, bacteria, or viruses. This taxonomic pluralism reflects both the large variety of species-level entities that exist in nature and the divergent emphasis that is placed on particular evolutionary phenomena by workers in different groups.

However, in advocating a strong pluralistic approach to species concepts, we do not wish to promote an equally pluralistic approach to naming species taxa. We would prefer named species taxa to be based on one species concept. In view of the fact that the large majority of named species-level entities has been based on a taxic approach in comparative biology, frequently based on morphological criteria, it could be argued that species names should be linked to a taxic concept (e. g. a phylogenetic species concept) and not to a genetic concept (e.g. the isolation concept). Our preference for species names based on a single taxonomic concept, preferably a phylogenetic species concept, may seem overly restrictive in that it prevents non-taxonomists from describing species taxa on the basis of other species concepts. However, a pluralistic approach would result in a greatly confused taxonomic system, as is already evident from the present situation since current systems are based on an amalgam of criteria. Therefore, species taxa should ideally be based on historical patterns that can be objectively recognized in nature. However, in view of current practice and pluralism in naming species (cf. Avise and Ball 1990; Frost and Hillis 1990; Ereshefsky 1994; De Queiroz 1995; Ghiselin 1995; Graybeal 1995; Wilson 1995, for contrasting opinions), we are not optimistic that this ideal situation shall be realized in the near future.

Then, how should one evaluate named species-level entities and determine whether these taxa are relevant for one's research? Workers in various biological disciplines should be cautious in taking 'species' from published lists or standard works at face value, and they need to verify the internal structure of different named entities whenever possible as well as inform themselves about known data on gene exchange and phylogenetic relationships with supposedly closely related entities. It may well be that different groupings that do not conform to 'accepted' taxonomy are actually more relevant to one's particular research interest.

Although proponents of genetic and phylogenetic concepts often seem to judge their own outlook as superior, this is in most cases only an expression of different research interests. In fact, process- and pattern-oriented species concepts are largely complementary to each other and each has its own reality: pattern analysis searches for common ancestries, thus offering direction to the analysis of process, while process analysis gives causal explanations to observed patterns of diversification. The employment of genetic species concepts in delimiting and naming species-level taxa has almost been limited to those groups in which the genetic characteristics are relatively easily observed, i.e. Recent higher vertebrates. With the rise of phylogenetic systematics (cladistics) and its associated phylogenetic approach of species, in which species are seen as those entities residing at the interface of 
hierarchical and reticulate relationships, contemporary taxonomic practice will probably produce an increasing number of binomials, many of which were formerly ranked as subspecies of a larger polytypic entity. Although traditionally oriented workers may not favour an increased number of Latin binomials, the real objective is to increase the information content of phylogenies and classifications, thus enhancing its predictive value to the benefit of workers in the widest possible array of biological disciplines. More refined taxonomies and classifications will offer workers in different disciplines better possibilities to determine and understand biodiversity. Surely, such taxonomies will be based on pattern-defined entities because systematics is a history-oriented endeavour. However, this does not imply that other groupings at the species level are not possible or relevant when research is process-oriented.

\section{Acknowledgements}

Prof. Dr. R. E. Ogren and the library staff of Wilkes College (Pennsylvania) are thanked for providing photocopies of some North American papers. RS acknowledges financial support from the Netherlands Organization for Scientific Research.

\section{References}

Avise, J. C. 1996. Threc fundamental contributions of molecular genetics to avian ecology and evolution. Ibis 138: 16-25.

Avise, J.C. and Ball, R. M. 1990. Principles of genealogical concordance in species concepts and biological taxonomy. Oxford Surveys in Evolutionary Biology 7: 45-67.

Ax, P. 1995. Das System der Metazoa l. Fischer Verlag, Stuttgart. 226pp.

Baum, D. 1992. Phylogenetic species concepts. Trends in Ecology and Evolution 7: 1-2.

Baum, D. A. and Donoghue, M. J. 1995. Choosing among alternative "phylogenetic" species concepts. Systematic Botany 20: 560-573.

Baum, D. A. and Shaw, K. L. 1995. Genealogical perspectives on the species problem. Pp. 289-303. In: Hoch, P. C. and Stephenson, A. G. (Eds) Experimental and Molecular Approaches to Plant Biosystematics. Monographs in Systematic Botany, Missouri Botanical Garden 53.

Blackman, R. L. 1995. What's in a name? Species concepts and realities. Bulletin of Entomological Research 85: 1-4.

Bush, G. L. 1994. Sympatric speciation in animals: new wine in old bottles. Trends in Ecology and Evolution 9: 285-288.

Coyne, J. A. 1992. Genetics and speciation. Nature 355: 511-515.

Cracraft, J. 1983. Species concepts and speciation analysis. Current Ornithology 1: 159-187.

Cracraft, J. 1987. Species concepts and the ontology of evolution. Biology and Philosophy 2: 329-346.

Cracraft, J. 1997. Species concepts in systematics and conservation biology - an ornithological viewpoint. Pp. 325-339. In: Claridge, M. F., Dawah, H. A. and Wilson, M. R. (Eds) Species: The Units of Biodiversity. Chapman and Hall, London.

Davis, J. I. 1996. Phylogenetics, molecular variation, and species concepts. BioScience 46: 502-510.

Davis, J.I, and Nixon, K.C.1992. Populations, genetic variation, and the delimitation of 
phylogenetic species. Systematic Biology 41: 421-435.

De Queiroz, K. 1995. The definitions of species and clade names: A reply to Ghiselin. Biology and Philosophy 10: 223-228.

Easter-Pilcher, A. 1996. Implementing the endangered species act. BioScience 46: 355-363.

Ereshefsky, M. 1991. Species, higher taxa, and the units of evolution. Philosophy of Science 58: 84-101.

Ereshefsky, M. 1992. Eliminative pluralism. Philosophy of Science 59: 671-690.

Ereshefsky, M. 1994. Some problems with the Linnaean hierarchy. Philosophy of Science 61: 186-205.

Frost, D. R. and Hillis, D. M. 1990. Species in concept and practice: herpetological applications. Herpetologica 46: 87-104.

Frost, D. R. and Kluge, A. G. 1994. A consideration of epistemology in systematic biology, with special reference to species. Cladistics 10: 259-294.

Geist, V. 1992. Endangered species and the law. Nature 357: 274-276.

Ghiselin, M. T. 1995. Ostensive definitions of the names of species and clades. Biology and Philosophy 10: 219-222.

Ghiselin, M. T. 1997. Metaphysics and the Origin of Species. SUNY Press, Albany. 377pp.

Graybeal, A. 1995. Naming species. Systematic Biology 44: 237-250.

Griffiths, P. E. 1994. Cladistic classification and functional explanation. Philosophy of Science 61: 206-227.

Groombridge, B. (ed.) 1992. Global Biodiversity. Chapman and Hall, London. 585pp.

Hazevoet, C. J. 1996. Conservation and species lists: taxonomic neglect promotes the extinction of endemic birds, as excmplified by taxa from eastern Atlantic islands. Bird Conservation International 6: 181-196.

Holsinger, K. E. 1984. The nature of biological species. Philosophy of Science 51: 293-307.

Horvath, C. D. 1997. Discussion: phylogenetic species concept: pluralism, monism, and history. Biology and Philosophy 12: 225-232.

Hull, D. L. 1997. The ideal species concept - and why we can't get it. Pp. 357-380. In: Claridge, M. F., Dawah, H. A. and Wilson, M. R. (Eds) Species: The Units of Biodiversity. Chapman and Hall, London.

Kitcher, P. 1984. Species. Philosophy of Science 51: 308-333.

Kitcher, P. 1987. Ghostly whispers: Mayr, Ghiselin, and the "philosophers" on the ontological status of species. Biology and Philosophy 2: 184-192.

Kitcher, P. 1989. Some puzzles about species. Pp. 183-208. In: Ruse, M. (Ed.) What the Philosophy of Biology Is. Kluwer Academic Publishers, Dordrecht.

Kornet, D. J. 1993. Reconstructing Species - Demarcations in Genealogical Networks. Ph. D. thesis, University of Leiden, The Netherlands. 120pp.

Lee, M.S. Y. 1995. Species concepts and the recognition of ancestors. Historical Biology 10: 329-339.

Mahner, M. 1993. What is a species? Journal for General Philosophy of Science 24: 103-126.

Mahner, M. and Bunge, M. 1997. Foundations of Biophilosophy. Springer, Berlin. 423pp.

Mallet, J. 1995. A species definition for the modern synthesis. Trends in Ecology and Evolution 10: 294-299.

Mayden, R. L. 1997. A hierarchy of species concepts: the denouement in the saga of the species problem. Pp. 381-424. In: Claridge, M. F., Dawah, H. A. and Wilson, M. R. (Eds) Species: The Units of Biodiversily. Chapman and Hall, London.

Mayr, E. 1942. Systematics and the Origin of Species. Columbia University Press, New York.

Mayr, E. 1992. A local flora and the biological species concept. American Journal of Botany 79: 
$222-238$.

Mayr, E. 1996. What is a species, and what is not? Philosophy of Science 63: 262-277.

Mishler, B. D. and Brandon, R. N. 1987. Individuality, pluralism, and the phylogenetic species concept. Biology and Philosophy 2: 397-414.

Mishler, B. D. and Donoghue, M. J. 1982. Species concepts: a case for pluralism. Systematic Zoology 31: 491-503.

O'Hara, R. J. 1993. Systematic generalization, historical fate, and the species problem. Systematic Biology 42: 231-246.

O'Hara, R. J. 1994. Evolutionary history and the species problem. American Zoologist 34: 12-22.

Paterson, H. E. H. 1985. The recognition concept of species. Pp. 21-29. In: Vrba, E. S. (Ed.) Species and Speciation. Transvaal Museum Monograph 4.

Popper, K. R. 1977. The Open Society and its Enemies. Vol. II. Routledge and Kegan Paul, London.

Rojas, M. 1992. The species problem and conservation: what are we protecting? Conservation Biology 6: 170-178.

Rosenberg, A. 1985. The Structure of Biological Science. Cambridge University Press, Cambridge. $281 \mathrm{pp}$.

Ruse, M. 1998. All my love is towards individuals. Evolution 52: 283-288.

Salthe, S. N. 1985. Evolving Hierarchical Systems. Columbia University Press, New York. 343pp.

Sluys, R. 1991. Species concepts, process analysis, and the hierarchy of nature. Experientia 47: $1162-1170$.

Sluys, R. 1996. The notion of homology in current comparative biology. Journal for Zoological Systematics and Evolutionary Research 34: 145-152.

Sober, E. 1984. Sets, species, and evolution: comments on Philip Kitcher's "species". Philosophy of Science 51: 334-341.

Stanford, P. K. 1995. For pluralism and against realism about species. Philosophy of Science 62 : $70-91$.

Sterelny, K. 1995. Punctuated equilibrium and macroevolution. Pp. 41-63. In: Griffiths, P. (Ed.) Trees of Life - Essays in Philosophy of Biology. Australian Studies in History and Philosophy of Science 11.

Valentine, J. W. and May, C. L. 1996. Hierarchies in biology and paleontology. Paleobiology 22: 23-33.

Van Valen, L. 1976. Ecological species, multispecies, and oaks. Taxon 25: 233-239.

Wiley, E. O. 1981. Phylogenetics: The Theory and Practice of Phylogenetic Systematics. Wiley \& Sons, New York. 439pp.

Wilson, B. E. 1995. A (not-so-radical) solution to the species problem. Biology and Philosophy 10: $339-356$.

Zink, R. M. 1996. Species concepts, speciation, and sexual selection. Journal of Avian Biology 27: 1-6.

Zink, R. M. 1997. Species concepts. Bulletin of the British Ornithologists' Club 117: 97-109.

Zink, R. M. and McKitrick, M. C. 1995. The debate over species concepts and its implications for ornithology. Auk 112: 701-719. 